\title{
Research on Modeling of Insider Trading and Equity Incentive
}

\author{
Zhengrui Xiang \\ School of Mathematics and Statistics, Beijing Institute of Technology, Beijing 100081, China; \\ xiang2260@vip.qq.com
}

Keywords: Insider Trading, Kyle Model, Equity Incentive, Real Sector.

\begin{abstract}
Due to the influence on the financial business field, insider trading has widely been paid attention on at home and abroad. This paper summarizes the development of the insider trading model domestic and overseas and the progress of the research of insider trading at home. Meanwhile, this paper puts forward a model, which is called benchmark model, which combines the real sector with financial markets to study insider trading. By using Bayesian Nash equilibrium solution, we can solve the benchmark model and then study the influence on insider trading caused by the financial markets. Therefore, the establishment of this model in this paper provides a strong basis for studying the relationship between the equity incentive contract and insider trading in the financial markets.
\end{abstract}

\section{Introduction}

Insider trading, as an interesting problem, has attracted a wide spread attention of overseas scholar [1-4]. Zhang and Zhu used the method called event study to certify that insider trading must exist in Chinese market, and even more serious than mature markets [5]. Therefore, it makes a great sense to study insider trading in depth at home. The research literature on insider trading of overseas scholars emerge in endlessly.

Miu and Zou expanded Kyle model by assuming the insider cannot get the complete information of the liquidation value of the risk assets and the market is not able to reach the standard semi-strong efficient market, analyzed the trading strategy and the final earnings of the insider again [6]. The research shows: the distortion of the information makes the insider more aggressively on trading. Zhang and Zhu came up with four hypotheses and then proved them: First, there must be insider trading in China. Second, insider trading is more serious than the mature markets in China. Third, the order of severity is in direct proportion to the give of the management in big events. Forth, insider trading center more on the bullish relationship [5]. Zhang and Zheng chose the issue of "Measures for the administration of equity incentive of listed companies (for Trial Implementation" as a chance, studied if there is insider trading in the companies which practiced the strategy later and found that equity incentive has positive effects to markets [7].

When a manager gets the insider information, there is possibility for him or her to short the equity, and this could destroy the benefits of the stockholder. Therefore, equity incentive is a good way to encourage the managers to work for the company but for themselves. Interestingly, Liu and Cao look into the relationship among management compensation, the stock price and market equilibrium under the general equilibrium framework [8]. It is found that in a market where short-selling is allowed extreme inefficiency would result if the management of a listed company did not receive extra compensation in one way or another even without taking into account the principle-agent issue. Under certain extreme parameters, there would be no market equilibrium. So, equity incentive is a perfect way to guarantee the fine operation of a company as well as the normal operation of markets. How to design reasonable plans for the salary and the equity incentive for the senior management of a listed company has been a main problem in economics and management for a long time.

This paper shall combine insider trading with equity incentive and extend the Kyle model on the basis of existing models. In the model, we take the real sector into consideration. 


\section{Kyle Model}

In 1985, Kyle built the classical insider trading model [3]. In the Kyle model, there are three kinds of traders: a single insider, market makers and uniformed noise traders. The insider gets an accurate insider information, and formulates equity trading strategy based on the information. The uniformed noise traders shield the insider because of the random trading. The market makers set prices efficiently conditional on information they have about the quantities traded by others. In this model, the insider get profits depends on the information, and noise traders suffer a loss. Half of the information is released and does not rely on exogenous variable.

\section{Extension of Kyle Model}

Holden \& Subrahmanyam bring the competition between insiders in the Kyle model [9]. Huddart \& Hughes \& Levine extend the Kyle model from the aspect of the rule of market trading [10]. Cao \& Ma bring the competition among insiders in their model [11]. Forster \& Viswanathan studied the heterogenization competition among insiders [12]. That is, not only is there competition among insiders, but also the insider's information is different. As a result, they found that the effectiveness of the profits and prices of the insiders are closely relevant to the relation of the insiders' information. Zhou [13] bring over-confidence on the basis of Foster \& Viswanathan [14]. But, the researches above only considered single financial market, ignored the real sector.

Thus, we built the model which makes an economy entity including the real sector and the financial market, and studied insider trading.

\section{The Build and the Application of the Benchmark Model}

Take an economy entity made of the real sector and the financial market. In the real sector, there are $\mathrm{N}+1$ companies which produce the same products, with no cost. The stockholder of company 1 hire a manager, who decide the output level of the company. The inverse demand function of the company 1 is below:

$q=(a-b Y) \tilde{z} a, b>0$

$\tilde{z}$ is a random variable which obeys the normal distribution, the average is $\bar{z}$, the variance is $\sigma_{z}^{2} \cdot q$ is the price of the product of company $1, Y=\sum_{i=1}^{N+1} y_{i}$ is the total output of all companies in the real sector. $y_{1}$ is the output of company $1, y_{i}, i=2 \ldots N+1$ is the output of company 2 to $\mathrm{N}+1$ respectively.

Only one of the companies above (company 1) is listed, so the assets traded in the financial market are actually the stocks of company 1 . The price of the stock (denoted by $v$ ) equals to the earnings per share of the companies. Assuming that company 1 holds one share, we have: $v=(a-b Y) y_{1} \tilde{z}$

When the manager of company 1 decides the output, he trades the stocks in the financial market according to his insider information at the same time. Also, the stockholders (the number of them is $\mathrm{M}$ ) in the company will participate in the trade of the stocks. We assume that the insider information they get is the same as the manager's.

There are three kinds of traders in the financial market. First is the insider, including the manager and the stockholders of company 1 . The insider information they got (denoted by $\theta$ ) is mixed with noise, and is always consistent. The specific form is below:

$\theta=\tilde{z}+\varepsilon$ 
$\theta$ is the insider information the manager gets, $\varepsilon$ and $\tilde{z}$ are independent noises, $\varepsilon \sim N\left(0, \sigma_{\varepsilon}^{2}\right)$. The volume of trade to submit is decided by the manager and the stockholders on the base of the insider information they got, denoted by $x_{i}$ ( $x_{1}$ is the volume of trade submitted by the manager, $x_{i}$, $i=2 \ldots N+1$ is the volume submitted by each of the $\mathrm{M}$ stockholders); then it comes to the noise traders, they get no insider information, the volume they submitted is demoted by $u$. Assuming that $u$ is a random variable, obey $u \sim N\left(0, \sigma_{u}^{2}\right)$, and it is independent from $\tilde{z}$ and $\varepsilon$; last is the market makers, they only observe the volume of traded and decide the price of the stock according to the data they have gotten.

The same as the Kyle model, at each auction trading takes place in two steps. In step one, the manager and the stockholders of company 1 choose the quantities they will trade on basis of the insider information. The market makers formulate the liner principle to set the price which aims at making the markets cleat. In step two, insiders and noise traders submit their quantities of trade, and market makers set the price according to the principle and the quantities above. The manager and the stockholders of company 1 only know the real value of $\theta$, but the exact value of $\varepsilon, u$; the market makers do not know the real value of $\tilde{z}$, they only know the distribution.

Because the information the manager and the noise traders get is different, the manager might choose to produce an infinite output (which will make the company go break), and shorts the stock of the company at the same time, aims at earning enormous profits. To avoid this situation, the company needs to give the manager some extra compensation. We assume it as equity incentive, that is give some stocks to the manager, more specifically:

$E I=B v$

Now, the profits of the manager (denoted by $\mathrm{G}_{1}$ ) are:

$G_{1}=E\left[(v-p) x_{1} \mid \theta\right]+E[B v \mid \theta]$

The profits of the stockholders (denoted by $\mathrm{G}_{\mathrm{i}}$ ) are:

$G_{i}=E\left[(v-p) x_{i} \mid \theta\right] i=2 \ldots M+1$

Now, on the base of the Kyle model, we build a model considering both the financial markets and the real sector, we can use Bayesian Nash equilibrium solution to study insider trading more deeply.

\section{Summary}

Insider information is the information that is known to the insiders and might affect the price of stock. Nowadays, the study of insider trading has received extensive attraction. At the same time this paper summing up the development of the insider trading model, it also summarized the research progress and the situation of application of the insider trading at home and abroad. At last, we used the economy entity made up of the real sector and the financial markets to build the benchmark model, which provide the theoretical model basis for us to use Bayesian Nash equilibrium solution, and then we can study the actual market situation of insider trading. So, for the insider trading of the economy entity mentioned above, this paper provides the theoretical model basis for studying it.

\section{References}

[1]. Kihlstrom R E, Mirman L J. Information and market equilibrium [J]. The Bell Journal of Economics, 1975: 357-376.

[2]. Grossman S J, Stiglitz J E. On the impossibility of informationally efficient markets[J]. The American economic review, 1980: 393-408.

[3]. Kyle A S. Continuous auctions and insider trading [J]. Econometrica: Journal of the Econometric Society, 1985: 1315-1335. 
[4]. Ausubel L M. Insider trading in a rational expectations economy [J]. The American Economic Review, 1990: 1022-1041.

[5]. Zhang X, Zhu H M. The economic analysis of insider trading[J]. China Economic Quarterly, 2003, 3(1): 72-96.

[6]. Miu X Q, Zou H F. The analysis of the trading behavior of insiders[J]. The Journal of World Economy, 2004, 39(11): 16-22.

[7]. Zhang Y, Zheng X Q. An enpirical study on the market reaction of equity incentive and insider trading[J]. East China Economic Mnagement, 2008, 22: 155-158.

[8]. Liu X F, Cao H. Fat cats, prices and market equilibrium: A theory [J]. China Economic Quarterly, 2010, 10(1): 209-226.

[9]. Holden C W, Subrahmanyam A. Long-l-lived private information and imperfect competition [J]. The Journal of Finance, 1992, 47(1): 247-270.

[10]. Huddart S, Hughes J S, Levine C B. Public disclosure and dissimulation of insider trades [J]. Econometrica, 2001, 69(3): 665-681.

[11]. Cao H H, Ma Y. Trade disclosure and imperfect competition among insiders [J]. University of California-Berkeley working paper, 1999.

[12]. Foster F D, Viswanathan S. Strategic trading when agents forecast the forecasts of others [J]. The Journal of Finance, 1996, 51(4): 1437-1478.

[13]. Zhou D. The virtue of overconfidence when you are not perfectly informed[J]. Economic Modelling, 2015, 47: 105-110.

[14]. Foster F D, Viswanathan S. Strategic trading with asymmetrically informed traders and long-lived information [J]. Journal of financial and Quantitative Analysis, 1994, 29(04): 499-518. 